\title{
Problema da falta de vagas em creches: matriz de loops e a priorização de causas de problemas complexos
}

\author{
José Osvaldo De Sordi \\ Faculdades Metropolitanas Unidas (FMU) e Faculdade Campo Limpo Paulista (Faccamp) \\ Reed Elliot Nelson \\ Universidade Nove de Julho (Uninove) e Southern Illinois University (SIU) \\ Pedro Reis Galindo \\ Prefeitura de Jundiaí/SP
}

\begin{abstract}
Dez milhões de crianças brasileiras deveriam frequentar creches, mas apenas $21 \%$ delas estão regularmente matriculadas. O problema da falta de vagas em creches foi o cenário escolhido para evidenciar a utilidade do artefato proposto: procedimentos para análise de problemas complexos, composto pela aplicação integrada entre mapa causal e matriz de loops, duas técnicas associadas aos estudos de padrões de cognição nas organizações. O artefato proposto foi testado junto a três municípios brasileiros, segundo os preceitos da abordagem design science. Causas e associações intercausais foram identificadas e priorizadas pela técnica de mapa causal e, posteriormente, interdependências entre causas foram analisadas pela técnica matriz de loops, o que alterou a priorização inicial. Evidenciou-se que para problemas complexos é fundamental identificar e analisar os loops entre loops de amplificação de desvio (loops "explosivos"). Outro resultado a destacar é a melhor compreensão de um problema complexo e socialmente relevante.
\end{abstract}

Palavras-chave: mapa causal; matriz de loops; creche; problema complexo; causa.

El problema de la insuficiente capacidad de guardería: loops matrix y la priorización de las causas de problemas complejos

De los diez millones de niños brasileños que por ley deberían estar en los programas de cuidado infantil patrocinados por el Estado, solo el 21\% están matriculados regularmente. Elegimos el problema de la falta de capacidad en la guardería como un escenario para demostrar la utilidad del artefacto propuesto: el análisis de problemas complejos utilizando mapa causal y loop matrix, dos técnicas tomadas del estudio de la cognición organizacional. El artefacto se probo en tres condados brasileños, utilizando los conceptos del design science research. Causas y asociaciones intercausais fueron identificados y

DOI: http://dx.doi.org/10.1590/0034-76121655

Artigo recebido em 24 jul. 2013 e aceito em 24 jul. 2014.

Rev. Adm. Pública - Rio de Janeiro 48(6):1407-1429, nov./dez. 2014 
priorizados por la técnica mapa causal y, posteriormente, las interdependencias entre las causas fueron analizados utilizando loop matrix, que cambiaron la priorización inicial. Mostró que para problemas complejos es esencial identificar y analizarlos circuitos de amplificación de la desviación entre los loops (loops "explosivos"). Otro resultado a destacar es la mejor comprensión de un problema complejo y socialmente relevante.

Palabras clave: mapa causal; loop matrix; guardería; problema complejo; causa.

The problem of insufficient capacity in daycare: loop matrices and the priorization of complex problems' causes

Ten million Brazilian children should be in state sponsored day care programs, but only $21 \%$ of them are regularly enrolled. We chose the problem of insufficient capacity in daycare as a setting to demonstrate the utility of a new problem analysis artifact: procedures for the analysis of complex problems, composed by the integrated application between cause maps and loop matrices, two techniques associated to the study of cognition standards in organizations. The proposed artifact was tested in three Brazilian municipalities using concepts from design science approach. Causes and intercause associations were identified and prioritized using cause map techniques and, subsequently, interactions between causes were analyzed using the loop matrix technique, which altered the initial prioritization. It was clear that, for complex problems, it is essential to identify and analyze the loops between loops of deviation amplifying ("explosive" loops). Another important result of this research is a better understanding of a complex and socially important problem.

KEYWoRDs: cause maps; loop matrix; daycare; complex problem; cause.

\section{Introdução}

O setor público lida com problemas complexos que envolvem a priorização e gestão de diversos recursos, demandas e interesses, abrangendo uma ampla gama de atores sociais e políticos. Especialmente no Brasil, onde a lei federal garante uma grande variedade de serviços sociais, similares aos encontrados no norte da Europa, sem a riqueza correspondente e a maturidade institucional para efetivamente entregar esses serviços, as dificuldades para priorização e gestão do setor público tornam-se ainda maiores. Nesse tipo de ambiente, há necessidade de métodos sofisticados para análise de problemas ao invés de pontuais medidas e critérios políticos da administração pública, embora se reconheça que a decisão final sempre terá um forte viés político. O presente artigo descreve uma abordagem para a análise de problemas complexos e como ela foi aplicada para análise do problema da falta de vagas em creches junto a três municípios brasileiros.

A Constituição Federal do Brasil (1988) declara como obrigação do Estado assegurar a educação infantil, em creche e pré-escola, às crianças com até cinco anos de idade, e indica o município como a esfera pública responsável pela educação infantil. Afirma, ainda, que a educação infantil é obrigatória para crianças a partir dos quatro anos de idade, sendo direito dessas e não de seus pais. O Estatuto da Criança e do Adolescente (Brasil, 1990) ampliou em um ano a faixa etária das crianças atendidas pelo serviço público de creches, assegurando 
atendimento para crianças de zero a seis anos de idade. O estatuto ainda atribui ao Estado a responsabilidade pela oferta e regularidade do serviço de creches. Dentro desse contexto legal, as autoridades municipais encontram-se obrigadas a prover serviços de creche às crianças de zero a seis anos, enquanto os pais devem encaminhar seus filhos para a educação infantil a partir dos quatro anos.

No Brasil estima-se em 10 milhões o total de crianças em idade de frequentar creches, mas apenas 21\% delas estão matriculadas em creches (Data, 2012). Segundo o Instituto Brasileiro de Geografia e Estatística, em 2011, o estado de São Paulo tinha 2.529.000 crianças na faixa etária entre zero e quatro anos, das quais apenas 771.000 frequentavam creches públicas ou privadas (Brasil, 2013). Não se pode considerar que as 1.758 .000 crianças não matriculadas em creches constituam a demanda não atendida, tendo em conta que muitas famílias não procuram o serviço de educação infantil, apesar da obrigatoriedade legal. De qualquer forma, mesmo com esse aspecto redutor da demanda não atendida, a insuficiência de vagas em creche é significativa:

Muitas mães não conseguem trabalhar porque não têm onde deixar os filhos pequenos em São Paulo. Cerca de $\mathbf{1 7 5}$ mil crianças estão na fila da creche na capital e a falta de vagas não é o único problema. Elas também reclamam que só conseguem matricular os filhos em creches que ficam longe do bairro onde moram. (G1.globo, 2012, grifo nosso)

Nos grandes centros brasileiros, as distâncias geográficas, as dificuldades de acesso, os movimentos migratórios, o surgimento de submoradias, a falta de dados descrevendo os pormenores do crescimento urbano e a falta de planejamento do crescimento da demanda por creches, entre outros aspectos, constituem uma rede ampla e imbricada de possíveis causas e efeitos, que tornam o problema da falta de vagas em creche ainda mais complexo. A relevância social e a complexidade, associadas à falta de vagas em creche, tornam este problema adequado para a presente pesquisa, que objetiva: evidenciar a utilidade e os procedimentos operacionais para aplicação do mapa causal e da matriz de loops para análise de problemas complexos no contexto da esfera pública. Assim, o contexto da falta de vagas em creches, além de ser apropriado para aplicação e discussão da técnica em questão, permite uma contribuição importante desta pesquisa no sentido de trazer melhor compreensão de um problema complexo, atual e relevante para a sociedade brasileira.

\section{Mapa causal e matriz de loops}

Para maior compreensão dos procedimentos necessários para utilização do artefato, descritos no quarto capítulo, conceituaremos e demonstraremos aqui a lógica que fundamenta as operações com matrizes, utilizadas tanto pelo mapa causal quanto pela matriz de loops. O mapa causal é uma representação matemática de relações do tipo causa e efeito percebidas entre as variáveis de um problema. A rigor, qualquer afirmação que tenha em conta relações 
causais recíprocas pode ser considerada um mapa causal. Por exemplo, a afirmação "Uso de drogas causa pobreza, mas pobreza não causa uso de drogas" satisfaz os critérios básicos para um mapa causal. Um loop, palavra inglesa que sugere circularidade, é uma afirmação da existência de uma relação causal recíproca. Na afirmação acima, não há nenhum loop, já que é postulada uma relação causal de drogas para pobreza, porém não há relação entre pobreza e uso de drogas.

Embora as pessoas constantemente façam atribuições causais no cotidiano, muito raramente identificam relações recíprocas entre diversas variáveis de forma clara e sistemática, o que ocasiona falta de rigor e precisão na análise e resolução de problemas complexos. Em função disso, destaca-se a importância do artefato objeto desta pesquisa, que explicita com clareza procedimentos que disciplinam e facilitam a execução das atividades lógicas necessárias para análise de interdependência entre causas.

Para fins de exemplificação, retornaremos à afirmação anterior sobre a relação entre uso de drogas e pobreza. O mapa causal é estruturado na forma de matriz quadrada que associa todas as possíveis causas entre si. Assim, utilizaremos uma matriz dois por dois, sendo "uso de drogas" descrito na primeira linha e a "pobreza" descrita na segunda linha da matriz. Para expressarmos que o "uso de drogas" causa "pobreza", colocamos " 1 " na segunda coluna da primeira linha. Não percebendo nenhuma outra relação causal, colocamos "0" nas demais células, o que resulta no mapa causal descrito na figura 1. Todas as manipulações no restante deste artigo são baseadas neste sistema de notação.

Figura 1

Exemplo de mapa causal

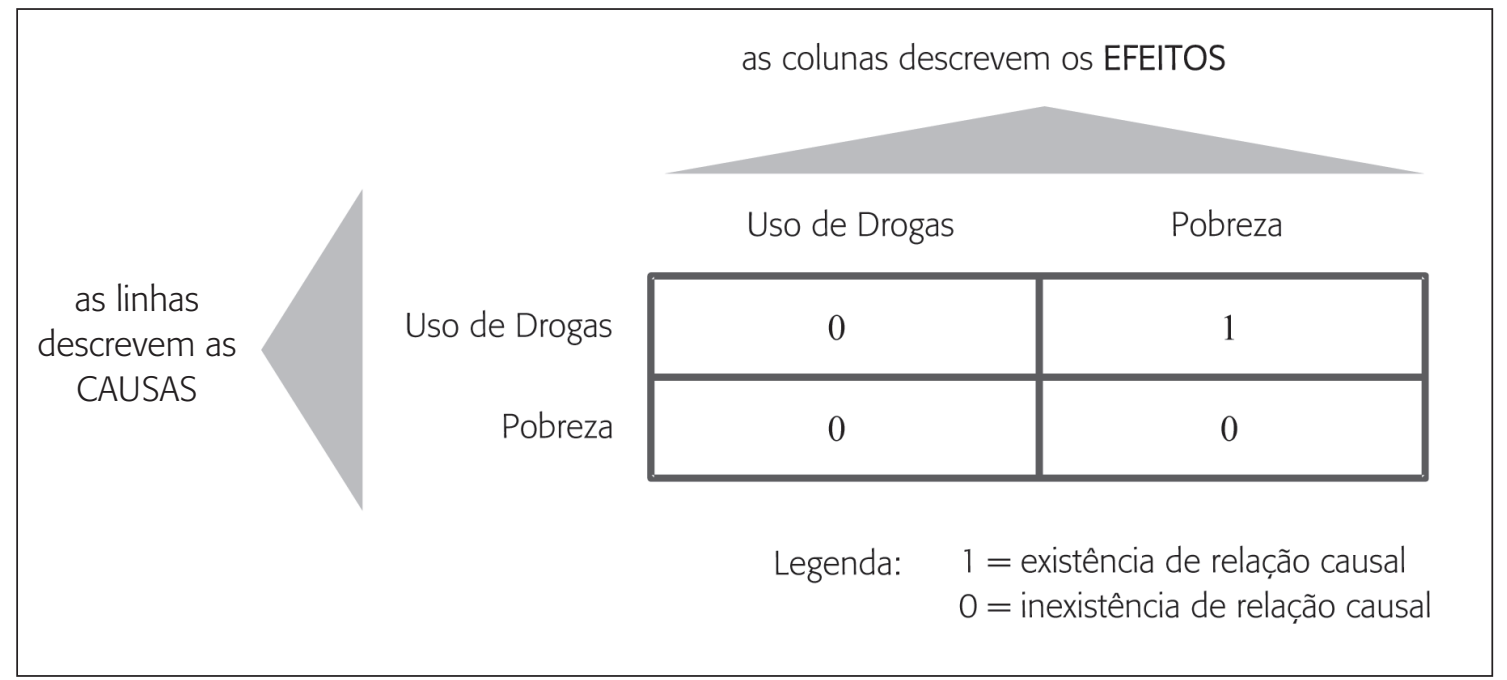

Fonte: Elaborada pelos autores.

Ponderações sobre a natureza do pensamento causal humano existem pelo menos desde os filósofos gregos e eram abordadas nos primórdios da sociologia e da psicologia, mas os 
primeiros esforços para representar pensamento causal matematicamente são atribuídos ao psicólogo Kelly (1955) e ao cientista político Axelrod (1976). A partir desses trabalhos clássicos tem florescido uma diversidade de abordagens e técnicas, sendo as de Bougon (1992) e Eden (2004) as mais desenvolvidas e proeminentes. Bougon enfatiza o uso de mapas causais para entender os processos cognitivos coletivos em organizações (Bugon, 1992; Bougon e Komocar, 1990; Bougon, Weick e Binkhorst, 1977), enquanto Eden enfatiza o uso de mapas causais como auxílio à análise e solução de problemas práticos (Eden, 2004; Eden e Ackermann, 1998; Eden, Jones e Sims, 1983). Este trabalho não faz uso específico de nenhuma das duas vertentes, porém utiliza representações matemáticas comuns às duas abordagens como principal recurso para discussão prática e social dos resultados alcançados.

As relações entre causas são bem explicadas pela teoria geral de sistemas, em especial pelos arquétipos sistêmicos: de amplificação de desvios, limitação de desvios e amplificação acelerada de desvios (Von Bertalanffy, 2008; Senge et al., 1994). O mapa causal quando desenvolvido na forma de matriz pode facilmente gerar a matriz de loop, que permite identificar rapidamente a amplificação de desvio (loop), assim como a identificação de espiral de amplificação acelerada de desvio (loop "explosivo"). O loop "explosivo" é caracterizado pela interseção de dois loops, de amplificação de desvios com mesmo movimento: ambos de incremento ou ambos de decremento. Intersecções entre dois loops com sinais opostos proporcionam loops de limitação de desvio, não ocorrendo a aceleração rápida enfatizada pelo adjetivo explosivo.

Há muitas variações de métodos e de técnicas, entre as diversas abordagens denominadas de mapa causal, a maioria delas não identificando loops sistêmicos entre causas. As operações e técnicas mais perceptíveis aos usuários e, também, as mais citadas na literatura envolvem a identificação e o entendimento das causas do problema, muitas vezes, confundidas como sendo a própria abordagem: "mapas causais são conhecidos por muitos nomes, incluindo diagrama de Ishikawa (espinha de peixe), diagrama causa e efeito, rodas de impacto, diagrama de árvore, mapas estratégicos e ferramentas de mapeamento de avaliação de risco" (Scavarda et al., 2006:264, tradução nossa). Essa visão se justifica considerando que a maioria dos problemas organizacionais não é de natureza complexa, sendo solucionados por técnicas mais simples e práticas em termos de operações e mecanismos de análises (Nelson e Mathews, 1991).

É muito importante ao gestor identificar os loops presentes no seu negócio. Não entender ou descuidar dos loops de limitação leva a ciclos erráticos e desgastantes de movimentos de expansão e contração. Não entender ou descuidar dos loops de amplificação pode significar perder as vantagens competitivas. Mais perigosos que os loops simples de amplificação ou de limitação são os loops de amplificação que se cruzam (Masuch, 1985), denominados neste artigo de loops "explosivos". O loop "explosivo" tem potencial para consumir todos os recursos e rapidamente destruir os sistemas. Nesse sentido, a detonação nuclear mostra-se uma boa analogia para a compreensão dos arquétipos sistêmicos aplicados no contexto da gestão. As partículas soltas da quebra de um núcleo detonam outros núcleos e assim por diante, até ser consumido todo material possível. Nos reatores nucleares, o processo de quebra é moderado por barras de grafite que absorvem algumas partículas, o que de outra forma detonaria todos 
os núcleos. Pode-se imaginar que as organizações precisam de dispositivos análogos às barras de controle dos reatores nucleares para evitar processos destrutivos desenfreados que podem comprometer a sua própria existência. Esses dispositivos de proteção são denominados na gestão de fatores críticos de sucesso (critical success factor), ou seja, os ativos ou competências organizacionais que não podem faltar ou falhar para que a organização mantenha sua competitividade e alcance seus objetivos (Aaker, 2005).

A depender do nível de complexidade dos problemas abordados, os gestores devem escolher a técnica mais adequada para análise das causas, com diferentes níveis de tratamento, inclusive de identificação dos arquétipos sistêmicos entre causas. Por exemplo, para problemas menos complexos, como os analisados pelas iniciativas de aprimoramento contínuo de processos organizacionais (seis sigmas, ${ }^{1}$ manufatura enxuta ${ }^{2}$ e gestão da qualidade total ${ }^{3}$ ), não é comum a aplicação de técnicas voltadas para identificação de loops e análise de interdependências entre loops. Nesses casos, as técnicas mais empregadas para análise de causas são: o diagrama de Ishikawa, para identificação e hierarquização de causas, e a matriz GUT, para definir as prioridades a partir da análise de gravidade, urgência e tendência de cada causa isolada (Kettinger, Tenge e Guha, 1997).

Quanto maior a quantidade de variáveis do problema, maior a dificuldade do gestor em identificar os loops. Isso demonstra a importância de o gestor ter domínio de abordagens para análise de causas que sejam capazes de identificar loops e inter-relação entre loops (loops "explosivos"). Este tipo de abordagem é o mais adequado para problemas complexos, como o tratado nesta pesquisa - falta de vagas em creches — , sendo o praticado nesta pesquisa, conforme já declarado no objetivo, ao citar a aplicação do mapa causal e da matriz de loops para análise de problemas complexos no contexto da esfera pública.

A abordagem mapa causal demanda a representação matemática dos relacionamentos causais percebidos, sendo estruturados e analisados como redes (network analysis) (Montibeller e Belton, 2006). Na abordagem apresentada neste artigo, utiliza-se de indicadores básicos da network analysis, como (Wasserman e Faust, 1994): o grau de saída (outdegree), para indicar a influência de uma causa nas demais, e o grau de entrada (indegree), para indicar o quanto uma causa é influenciada pelas demais. Além dos cálculos de indicadores de redes, as análises são complementadas com algumas operações com matrizes (multiplicação e transposição), todas descritas na seção de procedimentos da pesquisa.

No campo da ciência da administração a abordagem mapa causal, abrangendo a matriz de loop com identificação e análise de loops, tem sido empregada de forma bastante específica: o estudo de padrões de cognição nas organizações (Bougon, Weick e Binkhorst, 1977; Voyere e Faulkner, 1986). Bougon, Weick e Binkhorst (1977) buscaram compreender junto ao grupo de músicos, voluntários, de uma orquestra a percepção deles da entidade musical

\footnotetext{
${ }^{1}$ six sigma.

${ }^{2}$ lean manufacturing.

${ }^{3}$ total quality management.
} 
constituída. Outros estudos aplicaram a técnica dentro de métodos ou contextos específicos, por exemplo, a contribuição do mapa causal como meio de exploração e geração de sentido (sense making) aos esforços de gestão da mudança (Weber e Manning, 2001). Para o desenvolvimento dos métodos cognitivos, Nelson e Mathews (1991) discutiram a integração entre as técnicas mapa causal e de análise de redes; Nicolini (1999) explorou as diferenças entre dois métodos de mapeamento cognitivo da organização: mapa causal e representação social.

\section{Abordagem design science}

Segundo Hevner e colaboradores (2004:81, tradução nossa) "a abordagem design Science aplica-se a problemas importantes ainda não resolvidos, de forma única e inovadora, ou a problemas com soluções disponíveis, porém apresentando uma solução mais eficaz". Nesta pesquisa, a abordagem design science é aplicada no segundo contexto: apresenta e testa a utilidade de um novo artefato, a matriz de loops, que proporciona maior eficácia quando a questão é a análise de causas associadas a problemas complexos.

Gregor e Hevner (2013) classificam a abordagem design science quanto: a) aos níveis de contribuições possíveis e b) aos tipos de conhecimento gerados. As contribuições são classificadas em três níveis: o nível um é denominado de "implantação localizada do artefato" e, costumeiramente, caracteriza-se pela operação de um novo processo ou software. Os níveis dois e três são, respectivamente, "teoria derivada de projeto nascente" e "teoria derivada de projeto bem desenvolvido". A contribuição de nível um é explicada por Gregor e Hevner (2013:341, tradução nossa): "a demonstração de um novo artefato pode ser uma contribuição à pesquisa que incorpora ideias de projetos e teorias ainda a serem articuladas, formalizadas e totalmente compreendidas". O artefato desenvolvido, testado e descrito nesta pesquisa a caracteriza como de nível um. Quanto aos tipos de conhecimentos gerados pela abordagem design science, podem ser: invenção, aprimoramento e adaptação. O conhecimento do tipo aprimoramento concilia novas soluções para problemas já conhecidos, sendo esse o tipo de conhecimento gerado pela pesquisa descrita neste artigo: proposição de um artefato inovador (matriz de loops) para um problema já conhecido (falta de vagas em creches).

O conhecimento do tipo aprimoramento da abordagem design science está associado a contribuições prescritivas, do tipo "como" funciona o artefato (Gregor e Hevner, 2013). O conhecimento prescritivo explicita como fazer algo. Além das características do artefato, fornece as normas tecnológicas e as regras que determinam como alcançar um resultado desejado, em uma situação particular, com a utilização do artefato (Iivari, 2007; Kuechler e Vaishnavi, 2008). O resultado desejado está associado à característica da utilidade, premissa central da abordagem design science. Contrário ao paradigma da ciência comportamental, que busca encontrar "o que é verdade", a abordagem design science busca criar "o que é eficaz" (Hevner et al., 2004). A verificação da utilidade do artefato é destacada como uma das sete diretrizes da abordagem design science (Hevner et al., 2004): a) o objeto de estudo deve ser um artefato (design as an artifact), b) o problema que o artefato se propõe a resolver deve ser relevante (problem relevance), c) a avaliação da utilidade do artefato deve ser rigorosa (design 
evaluation), d) deve haver contribuição efetiva para a área de conhecimento do artefato (research contributions), e) a pesquisa deve ser rigorosa (research rigor), f) projeto envolvendo um processo interativo de pesquisa com testes (design as a search process), e g) comunicação dos resultados, inclusive para o público-alvo do artefato (communication of research).

Gab e colaboradores (2012), Iivari (2007), Kuechler e Vaishnavi (2008) desenvolveram taxionomias para melhor compreensão da abordagem design science. A taxionomia de Gab e colaboradores (2012), que se ocupam da forma prescritiva ou descritiva de como o conhecimento é apresentado, e a de Iivari (2007), Kuechler e Vaishnavi (2008), que se ocupam das normas tecnológicas e das regras que determinam como alcançar um resultado desejado, indicam dois momentos comuns do ciclo de desenvolvimento do artefato tecnológico: sua proposição na forma de proposta (descritiva) e sua apresentação na forma de como operacionalizá-lo (prescritiva). As diretrizes de Hevner e colaboradores (2004) para pesquisa design science agregam um terceiro estágio para o artefato: sua validação rigorosa, com comprovada utilidade no contexto da área fim, na qual o artefato se propõe a colaborar. Neste ponto é importante observar que há diferentes finalidades de testes: para construção e validação da lógica do artefato, por exemplo, a encontrada na proposição de uma escala, e o teste de utilidade do artefato, que deve estar associado a uma variável pertinente a um problema ou oportunidade do ambiente de negócios. A figura 2 descreve esses diferentes momentos do ciclo de desenvolvimento do artefato; os testes para construção e validação do artefato estão declarados como "artefato funcional", enquanto os testes para análise de utilidade estão descritos como "artefato testado".

Figura 2

Fases da pesquisa design science e os diferentes momentos do ciclo de desenvolvimento do artefato tecnológico

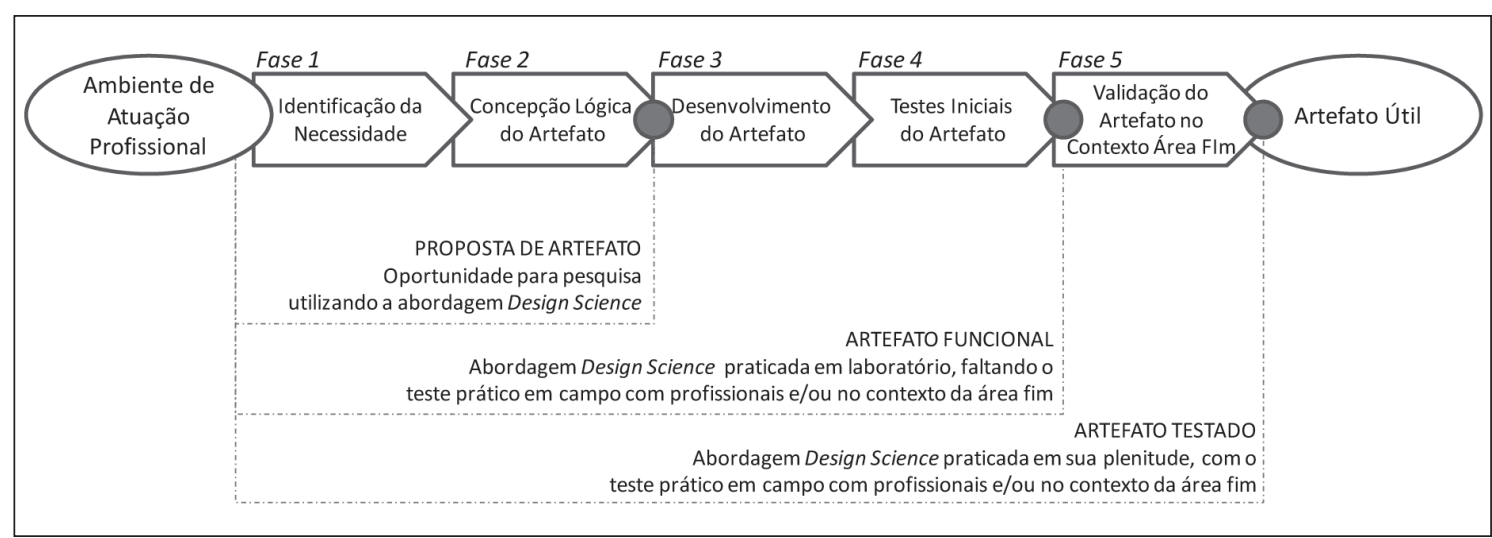

Fonte: Elaborada pelos autores.

Nesta pesquisa realizaram-se todas as fases de teste do artefato segundo a abordagem design science. O teste prático em campo da matriz de loops foi conduzido por gestores que tomam decisões complexas no contexto da esfera pública, mais especificamente, secretários 
e diretores que atuam junto a três municípios brasileiros. O método de aplicação do artefato por esses gestores está descrito na próxima seção.

\section{Procedimentos da pesquisa}

Epistemologicamente, esta pesquisa foi desenvolvida a partir de um paradigma de pesquisa pragmático (Creswell, 2007). A fim de evidenciar a utilidade do método proposto, optou-se pela aplicação do mesmo junto a três prefeituras, sendo essas atividades direcionadas a problema manifesto nessas entidades: a falta de vagas em creches. Em termos de estratégia de pesquisa, adotou-se a abordagem design science (Van Aken e Romme, 2009; Hevner et al., 2004), considerando que a pesquisa demandou:

a) explicitar e comprovar a utilidade de um artefato, caracterizado pelos procedimentos operacionais (método) para aplicação do mapa causal e da matriz de loops para análise de problemas complexos no contexto da esfera pública;

b) enfatizar a geração de conhecimento voltado para solução de problema, conectando a intervenção realizada a resultados, ou seja, foi intervencionista ao agir junto às prefeituras e trabalhar o entendimento cognitivo dos profissionais dessas entidades acerca das causas prioritárias para o problema da falta de vagas em creches.

A técnica de pesquisa utilizada para validar o artefato proposto foi a experimentação pragmática (Hevner et al., 2004). Os pesquisadores foram a campo e aplicaram o método proposto em sessões de trabalho promovidas conjuntamente com os secretários de educação dos municípios. As sessões para análise do problema de falta de vagas em creches ocorreram em três municípios do estado de São Paulo, conforme descritas no quadro 1. Essas sessões envolveram, em sua maioria, oito profissionais da prefeitura, dentre eles: secretários, diretores e assistentes, em sua grande maioria, lotados na Secretaria da Educação. Nas sessões estavam presentes dois pesquisadores, um operando os softwares e outro auxiliando na condução das atividades da sessão. As sessões de trabalho tiveram duração média de três horas e abrangeram, de forma sistemática, a realização de sete atividades, descritas nos parágrafos a seguir.

Quadro 1

Municípios nos quais ocorreram as sessões para análise do problema

\begin{tabular}{|crccc|}
\hline Município & \multicolumn{1}{c}{ População[ $^{[1]}$} & Serviço de Creche $^{[2]}$ & Governo & Sessão de Trabalho \\
\hline Guarulhos (SP) & 1.221 .979 & Tempo parcial & Continuidade & junho 2013 \\
Jundiaí (SP) & 370.126 & Tempo integral & nova gestão/partido & março 2013 \\
Salto (SP) & 105.516 & Tempo integral & nova gestão/partido & fevereiro 2013 \\
\hline
\end{tabular}

[1] Dados de 2010 do IBGE, Disponível em: <www.ibge.gov.br/cidadesat/index.php>.

[2] Tempo de permanência da criança na creche: até 6h, tempo parcial; de 8 h a 10h, tempo integral.

Fonte: Elaborado pelos autores. 
Para a atividade 1, de caracterização do problema, o secretário da educação e os pesquisadores abriam a sessão descrevendo o problema da falta de vagas em creches, destacando aspectos legais e eventos recentes em relação ao tema, a fim de caracterizar e justificar o problema a ser abordado na sessão de trabalho. Destacava-se a importância de a discussão ser direcionada para o âmbito da falta de vagas em creches no contexto das prefeituras, a fim de evitar a dispersão das discussões para temas fora da competência dos gestores municipais, por exemplo, se os serviços prestados pelas creches deveriam ser classificados como de natureza assistencial ou educacional.

Na atividade 2, de solicitação e registro das possíveis causas do problema, os pesquisadores solicitavam aos presentes que indicassem as possíveis causas do problema. Destacavam que, no primeiro momento, seria mais adequada a expressão de ideias de forma espontânea, declarando-as à medida que elas fossem surgindo, ou seja, praticar o princípio da livre fusão de diversas opiniões conforme postulado pela técnica de brainstorming (Osborn, 1993). Um dos pesquisadores digitava as causas sugeridas pelos presentes no editor de texto Word, sendo estas projetadas em uma tela ampla para que todos pudessem acompanhar a lista em desenvolvimento. Os presentes foram acomodados em cadeiras dispostas na forma de arco, permitindo a todos se verem, bem como enxergarem a tela de projeção.

A atividade 3, de consolidação, validação e compreensão da lista de causas, objetivou resumir a lista das possíveis causas em um conjunto de oito a 12 fatores. Adotou-se como procedimento: inclusão das causas mencionadas por todos, análise crítica das causas mencionadas por apenas uma pessoa e análise crítica das causas lembradas por último, em detrimento daquelas identificadas no início da sessão de trabalho (Osborn, 1993). À medida que as análises eram realizadas, a lista de causas era atualizada pelo pesquisador que operava o editor de texto. Observou-se, também, a ocorrência de causas com nomes semanticamente similares (falsos antônimos). Por exemplo, uma causa especificando "velocidade" e outra mencionando "prazo para terminar". Indagando com cuidado, observavase serem expressões de um mesmo fenômeno. Falsos sinônimos, ou seja, as causas podem parecer idênticas, porém distintas na essência, por exemplo, "atraso do cliente" e "atraso do funcionário" são causas similares, mas não idênticas (Osborn, 1993). Assim que o grupo identificava como concluída a lista de causas, o pesquisador que operava o editor de texto Word realizava a cópia da lista final de causas do problema para a base de dados do software especializado em análise de interdependências entre causas, denominado CNet. O software livre CNet implementa as operações com matrizes requeridas pela técnica de mapa causal.

Para a atividade 4, de solicitação e análise das relações intercausas (mapa causal), utilizou-se o software CNet. A partir da lista de causas, gerou-se uma matriz quadrada destas, denominada mapa causal (MC). Os pesquisadores projetaram o MC e solicitaram aos presentes que analisassem as possíveis interdependências entre cada par de causas. Destacaram os tipos de relações possíveis de serem registradas: relação causal positiva ou de incremento, indicada pelo numero " 1 ” (um) a ser assinalado na célula constituída pela 
interseção das duas causas. De forma análoga, relação causal negativa ou de decremento, indicada pelo número "-1" (menos um). A inexistência de interdependência (relações) era indicada pelo valor "0" (zero). Para não haver enganos em termos de interpretação das relações descritas no MC, os pesquisadores explicaram a ordem de leitura das causas da matriz: a causa descrita na linha representa a interventora ou a geradora do incremento ou decremento da causa descrita na coluna.

Para a atividade 5, de cálculo do índice de influência líquida, já com o MC concluído, os pesquisadores calcularam o outdegree ou grau de saída de cada causa, que indica o quanto a causa interfere em outras causas (somatório dos valores absolutos da linha da causa na MC), bem como o indegree ou grau de entrada, que indica o quanto a causa é influenciada pelas outras causas (somatório dos valores absolutos da coluna da causa na MC). Subtraindo o indegree do outdegree obteve-se o índice de influência líquida (IIL) de cada causa. Neste momento, os pesquisadores estimularam os participantes a observarem as causas com os maiores IIL. Destacou-se que estas oferecem os maiores benefícios ao gestor: demandam poucas alterações em outras causas (indegree baixo) e seu aprimoramento acarreta benefícios junto a muitas outras causas no sistema (outdegree alto). Até este momento, estas causas configuram-se como as mais importantes de serem consideradas pelos gestores para resolução do problema.

Na atividade 6, de geração e análise da matriz de loops, tendo concluído as análises iniciais pelo cálculo do IIL, os pesquisadores explicaram aos presentes a importância de identificar e analisar a interdependência entre causas, em especial as que se amplificam mutuamente, denominadas de loop de amplificação. Comentou-se que mais grave ainda são as interdependências entre dois ou mais loops de amplificação, denominadas de loop "explosivo", onde uma causa fora de controle pode iniciar um efeito em cadeia de amplificação de outras causas, podendo saturar os recursos do sistema. Feita esta explicação, utilizou-se o software CNet para gerar a matriz de loops (ML). As operações realizadas pelo CNet para tal foram: multiplicação elemento a elemento (Hadamard product) entre a matriz do mapa causal (MC) e sua matriz transposta $\left(\mathrm{MC}^{\mathrm{T}}\right)$, que resulta na matriz de loop $(\mathrm{ML}=\mathrm{MCoMC})$. Sendo a ML uma matriz simétrica, os somatórios dos valores da linha e da coluna da causa são iguais, sendo esse total denominado de total de loops. Observou-se que a causa prioritária deve ser a que apresenta maior valor para o total de loops, por indicar uma causa que participa simultaneamente de dois ou mais loops e, portanto, constitui um elemento integrador entre loops causais. Um descontrole da(s) variável(eis) associada(s) a essa causa pode disparar uma série de eventos que interferem em outras causas e que se amplificam mutuamente.

Concluiu-se a sessão de trabalho com a atividade 7 , de priorização das causas a receberem a atenção gerencial. Neste momento, os pesquisadores apresentaram a lista de causas com duas ordenações: primeira, em ordem decrescente pelo valor total de loops; segunda, em ordem decrescente pelo valor do IIL. Os pesquisadores destacaram que sem o segundo nível de análise, abrangendo a análise de interdependência entre loops, as causas a serem priorizadas para resolução do problema seriam bastante distintas. As sessões de trabalho foram en- 
cerradas buscando-se o consenso quanto às causas centrais, bem como com um entendimento quanto à ordem de prioridade destas. Os presentes também concluíam e comentavam quanto à importância de buscar os dois níveis de análises, não apenas identificar a inter-relação entre causas (loops), mas ir mais além, procurar compreender a interdependência entre pares de causa (loops entre loops).

Após cada sessão, os pesquisadores validavam entre si e com o profissional da prefeitura, responsável pela condução da sessão de discussão do problema da falta de vagas em creche, a sequência de procedimentos realizados e a melhor forma de aplicá-los e introduzi-los aos participantes das sessões a se realizar nas demais prefeituras.

O procedimento adotado para realização dos experimentos pragmáticos nas três prefeituras, com inclusão de atividades para identificação de loops e loops "explosivos", foi detalhadamente descrito nesta seção e pode ser assim resumido:

a) Caracterizar o problema - certificar que todos os participantes da seção de análise tenham compreensão do problema;

b) Solicitar e registrar as possíveis causas do problema - aplicar a técnica de brainstorming;

c) Consolidar, validar e compreender a lista de causas - excluir falsos antônimos e distinguir falsos sinônimos;

d) Solicitar e analisar as relações intercausas — preencher o mapa causal;

e) Calcular o índice de influência líquida (IIL) — subtrair o indegree (valor absoluto do quanto cada causa é influenciada por outra causa) do outdegree para cada causa;

f) Gerar e analisar a matriz de loops - multiplicar elemento a elemento (Hadamard product) da matriz do mapa causal pela sua matriz transposta;

g) Definir as causas a priorizar — calcular o indicador total de loops (soma das linhas ou colunas da matriz de loops).

\section{Dados coletados sobre o problema da falta de vagas em creches}

O quadro 2 apresenta a lista de causas identificadas junto aos gestores municipais para o problema da falta de vagas em creches, resultados obtidos ao término da atividade 3: "consolidação, validação e compreensão da lista de causas". A tipificação das causas foi realizada posteriormente pelos pesquisadores, com o propósito de buscar melhor compreensão da natureza do problema. Nas três localidades observaram-se causas associadas a questões de: instalação/edificação, financeira, geográfica/espaço físico, social, administrativa/gerencial. As causas com maior frequência nesses municípios são as de natureza social e administrativa/ gerencial, conforme pode se observar na tabela 1 . 
Quadro 2

\section{Causas identificadas junto aos gestores municipais para a falta de vagas em creches}

\begin{tabular}{|c|c|c|}
\hline \multirow{2}{*}{$\begin{array}{l}\text { Município e } \\
\text { Identificador }\end{array}$} & \multicolumn{2}{|r|}{ Causa Identificada } \\
\hline & Tipo de Causa & Descrição \\
\hline Guarulhos 1 & $\begin{array}{l}\text { Instalação / } \\
\text { Edificação }\end{array}$ & Infraestrutura insuficiente (falta de instalações) \\
\hline Guarulhos 2 & Financeira & Recursos financeiros insuficientes \\
\hline Guarulhos 3 & Financeira & Custo elevado do imóvel \\
\hline Guarulhos 4 & $\begin{array}{l}\text { Geográfica / } \\
\text { Espaço físico }\end{array}$ & Falta de terrenos apropriados (eleva custo da edificação) \\
\hline Guarulhos 5 & $\begin{array}{l}\text { Geográfica / } \\
\text { Espaço físico }\end{array}$ & Falta de terrenos nos locais da demanda (loteamentos clandestinos) \\
\hline Guarulhos 6 & Social & Explosão demográfica desordenada \\
\hline Guarulhos 7 & Social & Demanda de outros municípios (escolas limítrofes) \\
\hline Guarulhos 8 & $\begin{array}{l}\text { Administrativa / } \\
\text { Gerencial }\end{array}$ & $\begin{array}{l}\text { Convênio incipiente com o governo estadual para o atendimento do ensino } \\
\text { fundamental (compartilhar atendimento da demanda do 1o ao 5o ano, com o } \\
\text { direcionamento dos espaços da prefeitura para creches) }\end{array}$ \\
\hline Jundiaí 1 & Social & Especulação imobiliária (mais submoradias e moradias populares) \\
\hline Jundiaí 2 & $\begin{array}{l}\text { Administrativa / } \\
\text { Gerencial }\end{array}$ & Falta de diálogo entre áreas da prefeitura que aprovam projetos imobiliários e serviços \\
\hline Jundiaí 3 & Legislação & $\begin{array}{l}\text { Falta de legislação municipal que assegure projetos imobiliários abrangentes com visão } \\
\text { holística }\end{array}$ \\
\hline Jundiaí 4 & $\begin{array}{l}\text { Instalação / } \\
\text { Edificação }\end{array}$ & Falta de creches instaladas \\
\hline Jundiaí 5 & $\begin{array}{l}\text { Geográfica / } \\
\text { Espaço físico }\end{array}$ & Falta de áreas públicas para construção de novas creches (próximas da demanda) \\
\hline Jundiaí 6 & $\begin{array}{l}\text { Administrativa / } \\
\text { Gerencial }\end{array}$ & $\begin{array}{l}\text { Demora no trâmite legal de contratação e execução de serviços para construção e } \\
\text { entrega de creches }\end{array}$ \\
\hline Jundiaí 7 & $\begin{array}{l}\text { Administrativa / } \\
\text { Gerencial }\end{array}$ & $\begin{array}{l}\text { Falta de planejamento do crescimento da demanda a partir de dados demográficos } \\
\text { disponíveis na prefeitura }\end{array}$ \\
\hline Jundiaí 8 & Social & Uso indevido da creche pelas famílias (como repositório de crianças) \\
\hline Jundiaí 9 & Financeira & $\begin{array}{l}\text { Migração de crianças que pagavam escola particular para a bolsa creche (continuam } \\
\text { na mesma escola particular/paga, conveniada com a prefeitura, porém com apoio } \\
\text { financeiro da prefeitura e não mais dos pais) }\end{array}$ \\
\hline Jundiaí 10 & Social & $\begin{array}{l}\text { Residentes de outros municípios que trabalham em Jundiaí e trazem suas crianças às } \\
\text { creches de Jundiaí (utilização do endereço do empregador) }\end{array}$ \\
\hline Jundiaí 11 & Social & Serviços prestados em tempo integral nas creches são atraentes aos pais \\
\hline Jundiaí 12 & Legislação & $\begin{array}{l}\text { Dificuldade política e legal para redução do tempo de permanência das crianças nas } \\
\text { creches para meio período }\end{array}$ \\
\hline Salto 1 & Social & $\begin{array}{l}\text { Ampla atratividade do serviço (não exclusivo à população carente, classe média utiliza } \\
\text { por ser serviço de qualidade) }\end{array}$ \\
\hline
\end{tabular}




\begin{tabular}{|c|c|c|}
\hline \multirow{2}{*}{$\begin{array}{l}\text { Município e } \\
\text { Identificador }\end{array}$} & \multicolumn{2}{|r|}{ Causa Identificada } \\
\hline & Tipo de Causa & Descrição \\
\hline Salto 2 & Social & Excesso de crianças por família (criança vista como fonte de renda) \\
\hline Salto 3 & Social & Cumprir ordens judiciais para abertura de vagas em creche sem regulamentação \\
\hline Salto 4 & Social & $\begin{array}{l}\text { Maior compreensão do direito da família pelo uso da creche como depósito (dia todo, } \\
\text { funcionam } 12 \mathrm{~h} \text { as creches de Salto) }\end{array}$ \\
\hline Salto 5 & $\begin{array}{l}\text { Recursos } \\
\text { Humanos }\end{array}$ & Absenteísmo elevado dos funcionários públicos (muitas faltas e atestados) \\
\hline Salto 6 & $\begin{array}{l}\text { Recursos } \\
\text { Humanos }\end{array}$ & $\begin{array}{l}\text { Pouca oferta de funcionários para se escolher pessoas com perfil adequado (CLT e } \\
\text { salário pouco atrativo) }\end{array}$ \\
\hline Salto 7 & Financeira & Alto custo da operação e manutenção da creche \\
\hline Salto 8 & $\begin{array}{l}\text { Administrativa / } \\
\text { Gerencial }\end{array}$ & Ausência da previsão da demanda por áreas da cidade \\
\hline Salto 9 & $\begin{array}{l}\text { Geográfica / } \\
\text { Espaço físico }\end{array}$ & Escassez de área/imóvel para novas creches \\
\hline Salto 10 & $\begin{array}{l}\text { Administrativa / } \\
\text { Gerencial }\end{array}$ & Contratação da construção com problemas de projeto e memorial descritivo \\
\hline Salto 11 & $\begin{array}{l}\text { Instalação / } \\
\text { Edificação }\end{array}$ & $\begin{array}{l}\text { Instalações inadequadas (projeto de construção financiado pelo poder público tem de } \\
\text { ser adaptado e se perdem vagas com adaptações das instalações) }\end{array}$ \\
\hline Salto 12 & $\begin{array}{l}\text { Administrativa / } \\
\text { Gerencial }\end{array}$ & $\begin{array}{l}\text { Falta de sistema de planejamento e alocação da demanda que permita melhor } \\
\text { otimização dos espaços e vagas disponíveis }\end{array}$ \\
\hline
\end{tabular}

Fonte: Elaborado pelos autores.

\section{Tabela 1}

\section{Diversidade e frequência das causas identificadas nos municípios}

\begin{tabular}{|ccccccccc|}
\hline \multirow{2}{*}{ Município } & \multicolumn{7}{c|}{ Tipo de Causa } \\
\cline { 2 - 9 } & $\begin{array}{c}\text { Instalação / } \\
\text { Edificação }\end{array}$ & Financeira & $\begin{array}{c}\text { Geográfica / } \\
\text { Espaço físico }\end{array}$ & Social & $\begin{array}{c}\text { Administrativa / } \\
\text { Gerencial }\end{array}$ & Legislação & $\begin{array}{c}\text { Recursos } \\
\text { Humanos }\end{array}$ \\
\hline Guarulhos & 1 & 2 & 2 & 2 & 1 & 0 & 0 \\
Jundiaí & 1 & 1 & 1 & 4 & 3 & 2 & 0 \\
Salto & 1 & 1 & 1 & 4 & 3 & 2 & 2 \\
TOTAL & 3 & 4 & 4 & 10 & 7 & 2 & 2 \\
\hline
\end{tabular}

Fonte: Elaborada pelos autores.

As listas iniciais de causas identificadas ao término da atividade 2, "solicitação e registro das possíveis causas do problema", totalizaram 22 causas, tanto para o município de Jundiaí quanto para Salto, sendo estas consolidadas em 12 causas centrais nos dois municípios. Para o município de Guarulhos observou-se inicialmente 12 causas, que resultaram em oito causas. Observa-se que as coletas de dados foram realizadas nos primeiros meses dos governos muni- 
cipais, referentes ao quatriênio 2013-16. Dos três municípios analisados somente Guarulhos apresentava continuidade do governo, nos demais ocorreram mudanças significativas: alteração de prefeito e de partido político. Este aspecto pode ter impactado na menor detecção de causas para o município de Guarulhos. Ao analisar a diversidade de causas identificadas nos municípios, descritas na tabela 1 , observa-se que as causas centrais identificadas para os municípios com mudança de governo foram de ordem social e administrativa-gerencial, totalizando, respectivamente, quatro e três causas desses tipos, para as duas cidades. Outro aspecto, mais objetivo, que explica a menor quantidade e diversidade de causas identificadas no município de Guarulhos é o tempo de permanência das crianças nas creches: a única das três que trabalha com meio período (tempo parcial), conforme descrito no quadro 1.

\section{Análises e discussões referentes ao problema da falta de vagas em creches}

O primeiro nível de análise de interdependências entre as causas ocorreu no ato do preenchimento do mapa causal. Por se tratar de uma matriz quadrada, que associa todas as causas entre si, o mapa causal permite a análise de todas as opções possíveis de interdependência entre as causas identificadas para o problema. Este momento da sessão demandou muito diálogo e análises entre os participantes da sessão de análise. As células do mapa causal, formadas pela interseção entre duas causas, foram preenchidas com os valores: "-1" (menos um), "1" (um), ou "0" (zero), conforme as instruções descritas na Atividade 4 — "Solicitação e análise das relações intercausas (mapa causal)". A tabela 2 apresenta o mapa causal gerado para a prefeitura de Jundiaí.

Tabela 2

Mapa causal para o problema da falta de vagas em creches no contexto da prefeitura de Jundiaí

\begin{tabular}{|c|c|c|c|c|c|c|c|c|c|c|c|c|}
\hline Associações entre as Causas Identificadas & 1 & 2 & 3 & 4 & 5 & 6 & 7 & 8 & 9 & 10 & 11 & 12 \\
\hline $\begin{array}{l}\text { 1. Especulação imobiliária (mais submoradias e } \\
\text { moradias populares) }\end{array}$ & 0 & 0 & 1 & 1 & 1 & 0 & 0 & 0 & 0 & 0 & 0 & 0 \\
\hline $\begin{array}{l}\text { 2. Falta de diálogo entre áreas da prefeitura que } \\
\text { aprovam projetos imobiliários e serviços }\end{array}$ & 1 & 0 & 1 & 0 & 1 & 0 & 1 & 0 & 0 & 0 & 0 & 0 \\
\hline $\begin{array}{l}\text { 3. Falta de legislação municipal que assegure projetos } \\
\text { imobiliários abrangentes com visão holística }\end{array}$ & 1 & 1 & 0 & 1 & 0 & -1 & 0 & 0 & 0 & 0 & 0 & 0 \\
\hline 4. Falta de creches instaladas & 0 & 0 & 0 & 0 & 0 & 0 & 0 & 0 & 1 & 0 & 0 & 0 \\
\hline $\begin{array}{l}\text { 5. Falta de áreas públicas para construção de novas } \\
\text { creches (próximo da demanda) }\end{array}$ & 0 & 0 & 0 & 1 & 0 & 1 & 0 & 0 & 0 & 0 & 0 & 0 \\
\hline $\begin{array}{l}\text { 6. Demora no trâmite legal de contratação e execução } \\
\text { de serviços para construção e entrega de creches }\end{array}$ & 0 & 0 & 0 & 1 & 0 & 0 & 0 & 0 & 1 & 0 & 0 & 0 \\
\hline
\end{tabular}




\begin{tabular}{|c|c|c|c|c|c|c|c|c|c|c|c|c|}
\hline Associações entre as Causas Identificadas & 1 & 2 & 3 & 4 & 5 & 6 & 7 & 8 & 9 & 10 & 11 & 12 \\
\hline $\begin{array}{l}\text { 7. Falta de planejamento do crescimento da demanda } \\
\text { a partir de dados demográficos disponíveis na } \\
\text { prefeitura }\end{array}$ & 0 & 0 & 0 & 1 & 1 & 1 & 0 & 0 & 1 & 0 & 0 & 0 \\
\hline $\begin{array}{l}\text { 8. Uso indevido da creche (como repositório de } \\
\text { crianças) }\end{array}$ & 0 & 0 & 0 & 0 & 0 & 0 & 0 & 0 & 1 & 0 & 0 & 0 \\
\hline $\begin{array}{l}\text { 9. Migração de crianças que pagavam escola particular } \\
\text { para a bolsa creche (continuam na mesma escola } \\
\text { conveniada com a prefeitura - paga -, porém com } \\
\text { apoio financeiro da prefeitura e não mais dos pais) }\end{array}$ & 0 & 0 & 0 & 0 & 0 & 0 & 1 & 0 & 0 & 0 & 0 & 0 \\
\hline $\begin{array}{l}\text { 10. Residentes de outros municípios que trabalham } \\
\text { em Jundiaí e trazem suas crianças às creches de } \\
\text { Jundiaí (com endereço falso) }\end{array}$ & 0 & 0 & 0 & 0 & 0 & 0 & 1 & 1 & 0 & 0 & 0 & 0 \\
\hline $\begin{array}{l}\text { 11. Serviços prestados em tempo integral nas creches } \\
\text { são atraentes aos pais }\end{array}$ & 0 & 0 & 0 & 1 & 0 & 0 & 0 & 1 & 1 & 1 & 0 & 1 \\
\hline $\begin{array}{l}\text { 12. Dificuldade política e legal (constituição) em } \\
\text { reduzir o tempo de atendimento das creches para } \\
\text { meio período }\end{array}$ & 0 & 0 & 0 & 0 & 0 & 0 & 0 & 1 & 1 & 1 & 1 & 0 \\
\hline
\end{tabular}

Fonte: Elaborada pelos autores.

Assim que o mapa causal era concluído, calculava-se o índice de influência líquida (IIL), conforme as instruções já descritas na atividade 5. A tabela 3 apresenta os valores de IIL obtidos para as causas do problema da falta de vagas, segundo o contexto analisado para as três prefeituras. Para o município de Jundiaí, a causa 11, "Serviços prestados em tempo integral nas creches são atraentes aos pais", é a que apresenta o índice de influência líquida mais forte. Ela influencia cinco variáveis e é influenciada por somente uma. Isto é, para mudar a causa 11, precisa-se mexer pouco com outras causas, apenas uma, porém uma melhora nesta causa acarretará benefícios junto a muitas outras causas no sistema, impacta cinco causas.

A causa identificada com maior IIL para a prefeitura de Guarulhos foi a causa 4: "Falta de terrenos apropriados (eleva custo da edificação)". Para o município de Salto, duas causas apresentaram o maior valor para o IIL, as causas 2 e 9, respectivamente, "Excesso de crianças por família (criança vista como fonte de renda)" e "Escassez de área/imóvel para novas creches". Essas estatísticas básicas podem ajudar os gestores a decidirem onde e quando agir para melhorar o desempenho do sistema. Para resolução do problema, mais importante que a identificação da causa com maior IIL é a identificação das variáveis que influenciam reciprocamente um movimento sistêmico denominado de loop, abordado a seguir. 
Tabela 3

IIL e total de loops calculado para cada uma das causas

\begin{tabular}{|c|c|c|c|c|c|c|c|c|c|c|c|c|c|}
\hline \multirow{2}{*}{$\frac{\cdot \frac{0}{2}}{\frac{0}{\frac{D}{5}}}$} & \multirow{2}{*}{ Indicador } & \multicolumn{12}{|c|}{ Causa Identificada } \\
\hline & & 1 & 2 & 3 & 4 & 5 & 6 & 7 & 8 & 9 & 10 & 11 & 12 \\
\hline \multirow{4}{*}{ 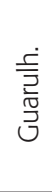 } & Outdegree & 2 & 1 & 2 & 4 & 2 & 3 & 2 & 2 & & & & \\
\hline & Indegree & 7 & 7 & 1 & 0 & 2 & 0 & 0 & 1 & & & & \\
\hline & IIL & -5 & -6 & 1 & 4 & 0 & 3 & 2 & 1 & & & & \\
\hline & Total Loops & 2 & 1 & 0 & 0 & 0 & 0 & 0 & 1 & & & & \\
\hline \multirow{4}{*}{ 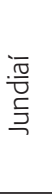 } & Outdegree & 3 & 4 & 4 & 1 & 2 & 2 & 4 & 1 & 1 & 2 & 5 & 4 \\
\hline & Indegree & 2 & 1 & 2 & 6 & 3 & 3 & 3 & 3 & 6 & 2 & 1 & 1 \\
\hline & IIL & 1 & 3 & 2 & -5 & -1 & -1 & 1 & -2 & -5 & 0 & 4 & 3 \\
\hline & Total Loops & 1 & 1 & 2 & 0 & 0 & 0 & 1 & 0 & 1 & 0 & 1 & 1 \\
\hline \multirow{4}{*}{$\frac{\stackrel{P}{\sqrt[N]{N}}}{\sqrt{n}}$} & Outdegree & 3 & 3 & 1 & 1 & 2 & 0 & 0 & 1 & 3 & 3 & 1 & 2 \\
\hline & Indegree & 2 & 0 & 5 & 2 & 1 & 0 & 7 & 0 & 0 & 1 & 2 & 0 \\
\hline & IIL & 1 & 3 & -4 & -1 & 1 & 0 & -7 & 1 & 3 & 2 & -1 & 2 \\
\hline & Total Loops & 0 & 0 & 0 & 0 & 0 & 0 & 0 & 0 & 0 & 0 & 0 & 0 \\
\hline
\end{tabular}

Fonte: Elaborada pelos autores.

O benefício mais importante do mapa causal é a capacidade de identificar os loops, em especial os loops "explosivos" do sistema. É um diagnóstico simples que consome pouquíssimos recursos, mas pode identificar problemas subjacentes muito perigosos à organização que dificilmente seriam enxergados de outra forma. Identifica-se loop examinando simultaneamente fileiras e colunas com o objetivo de encontrar causalidade recíproca. Em termos matemáticos, procura-se a presença de um efeito causal mútuo na célula Cij, e na célula Cji da matriz. Causas nas duas células indicam a presença de um loop. Se ambas as células têm o mesmo sinal (seja positivo ou negativo), há um loop de amplificação de desvios, se os sinais são diferentes, há um loop de limitação de desvios.

A busca por loops realizada dessa forma, analisando os valores para cada par de variáveis causais, é lenta, cansativa e sujeita a erros. Operações matriciais simples podem realizar rapidamente essa atividade, conforme procedimentos descritos na atividade 6 — "Geração e análise da matriz de loops". As operações envolvem a multiplicação elemento a elemento (Hadamard product) da matriz original, o mapa causal, pela sua matriz transposta. A tabela 4 apresenta a matriz de loop gerada para a prefeitura de Jundiaí. Para verificar se há a presença de loops "explosivos" no mapa causal em análise, basta averiguar se algum indicador total de loops (somatório das linhas ou colunas) apresenta valor superior a 1. Para a prefeitura de Jundiaí, observa-se a existência de um loop "explosivo", tendo como causa central na interseção dos dois loops a causa 3: "Falta de legislação municipal que assegure projetos imobiliários 
abrangentes com visão holística". Voltando à tabela 3, observa-se que para a prefeitura de Guarulhos há um loop "explosivo", tendo como causa central na interseção dos dois loops a causa 2: "Recursos financeiros insuficientes". Para o município de Salto, não se identificaram loops "explosivos".

Tabela 4

Matriz de loop para o problema da falta de vagas em creches no contexto da prefeitura de Jundiaí

\begin{tabular}{|c|c|c|c|c|c|c|c|c|c|c|c|c|c|}
\hline Loops entre Causas & 1 & 2 & 3 & 4 & 5 & 6 & 7 & 8 & 9 & 10 & 11 & 12 & $\Sigma$ \\
\hline $\begin{array}{l}\text { 1. Especulação imobiliária (mais submoradias e moradias } \\
\text { populares) }\end{array}$ & 0 & 0 & 1 & 0 & 0 & 0 & 0 & 0 & 0 & 0 & 0 & 0 & 1 \\
\hline $\begin{array}{l}\text { 2. Falta de diálogo entre áreas da prefeitura que aprovam } \\
\text { projetos imobiliários e serviços }\end{array}$ & 0 & 0 & 1 & 0 & 0 & 0 & 0 & 0 & 0 & 0 & 0 & 0 & 1 \\
\hline $\begin{array}{l}\text { 3. Falta de legislação municipal que assegure projetos } \\
\text { imobiliários abrangentes com visão holística }\end{array}$ & 1 & 1 & 0 & 0 & 0 & 0 & 0 & 0 & 0 & 0 & 0 & 0 & 2 \\
\hline 4. Falta de creches instaladas & 0 & 0 & 0 & 0 & 0 & 0 & 0 & 0 & 0 & 0 & 0 & 0 & 0 \\
\hline $\begin{array}{l}\text { 5. Falta de áreas públicas para construção de novas cre- } \\
\text { ches (próximo da demanda) }\end{array}$ & 0 & 0 & 0 & 0 & 0 & 0 & 0 & 0 & 0 & 0 & 0 & 0 & 0 \\
\hline $\begin{array}{l}\text { 6. Demora no trâmite legal de contratação e execução de } \\
\text { serviços para construção e entrega de creches }\end{array}$ & 0 & 0 & 0 & 0 & 0 & 0 & 0 & 0 & 0 & 0 & 0 & 0 & 0 \\
\hline $\begin{array}{l}\text { 7. Falta de planejamento do crescimento da demanda a } \\
\text { partir de dados demográficos disponíveis na prefeitura }\end{array}$ & 0 & 0 & 0 & 0 & 0 & 0 & 0 & 0 & 1 & 0 & 0 & 0 & 1 \\
\hline 8. Uso indevido da creche (como repositório de crianças) & 0 & 0 & 0 & 0 & 0 & 0 & 0 & 0 & 0 & 0 & 0 & 0 & 0 \\
\hline $\begin{array}{l}\text { 9. Migração de crianças que pagavam escola particular } \\
\text { para a bolsa creche (continuam na mesma escola con- } \\
\text { veniada com a prefeitura - paga -, porém com apoio } \\
\text { financeiro da prefeitura e não mais dos pais) }\end{array}$ & 0 & 0 & 0 & 0 & 0 & 0 & 1 & 0 & 0 & 0 & 0 & 0 & 1 \\
\hline $\begin{array}{l}\text { 10. Residentes de outros municípios que trabalham em } \\
\text { Jundiaí e trazem suas crianças às creches de Jundiaí } \\
\text { (com endereço falso) }\end{array}$ & 0 & 0 & 0 & 0 & 0 & 0 & 0 & 0 & 0 & 0 & 0 & 0 & 0 \\
\hline $\begin{array}{l}\text { 11. Serviços prestados em tempo integral nas creches são } \\
\text { atraentes aos pais }\end{array}$ & 0 & 0 & 0 & 0 & 0 & 0 & 0 & 0 & 0 & 0 & 0 & 1 & 1 \\
\hline $\begin{array}{l}\text { 12. Dificuldade política e legal (constituição) em reduzir o } \\
\text { tempo de atendimento das creches para meio período }\end{array}$ & 0 & 0 & 0 & 0 & 0 & 0 & 0 & 0 & 0 & 0 & 1 & 0 & 1 \\
\hline Somatório das Colunas & 1 & 1 & 2 & 0 & 0 & 0 & 1 & 0 & 1 & 0 & 1 & 1 & 8 \\
\hline
\end{tabular}

Fonte: Elaborada pelos autores.

A tabela 3 evidencia a existência de diferença significativa no resultado da análise, a depender do nível de análise realizada, caracterizada pelos indicadores IIL e total de loops, ob- 
tidos, respectivamente, pelo mapa causal e pela matriz de loops. Para o município de Jundiaí, o IIL indicava a causa 11, "Serviços prestados em tempo integral nas creches são atraentes aos pais" como a mais prioritária. Porém, com um segundo nível de análise, com a matriz de loop considerando a interdependência entre as causas, observou-se que a causa mais prioritária era de fato a causa 3: "Falta de legislação municipal que assegure projetos imobiliários abrangentes com visão holística". Para o município de Guarulhos também houve alteração de prioridade entre causas após o segundo nível de análise. O IIL indicava a causa 4: "Falta de terrenos apropriados (eleva custo da edificação)" como mais prioritária, enquanto o indicador de total de loops apontou a causa 2: "Recursos financeiros insuficientes".

Para geração do indicador total de loops não há a necessidade do cálculo do IIL, basta o mapa causal para que se possa gerar a matriz de loops. Apesar da não obrigatoriedade do cálculo do IIL, a análise realizada na prefeitura de Salto evidenciou a importância de os métodos e ferramentas (softwares) contemplarem o cálculo e a apresentação do IIL. No caso da prefeitura de Salto, cuja rede constituída pelo mapa causal apresentava baixa densidade, loops causais não foram observados. Assim, para o município de Salto, o direcionamento do problema em termos de priorização das causas se deu por intermédio do IIL.

\section{Conclusões}

Os experimentos pragmáticos para análise do problema da falta de vagas em creches, conduzidos junto aos três municípios, evidenciaram que as investigações causais de problemas complexos não devem se restringir aos aspectos individuais ou mesmo às análises intercausais. É essencial a identificação das relações simétricas e inter-relacionadas entre as causas, ou seja, os laços fortes denominados de loops, bem como os entrelaçamentos de loops, denominados de loops "explosivos". Observou-se que a identificação e contagem dos loops "explosivos", por intermédio da matriz de loops e do indicador total de loops, alteraram as prioridades das causas inicialmente definidas segundo o mapa causal e o IIL. Destarte, as alterações das causas prioritárias pela execução das sete atividades da pesquisa, bem como o detalhamento dos procedimentos realizados nessas atividades, são informações centrais ao atendimento do objetivo dessa pesquisa: evidenciar a utilidade e os procedimentos operacionais para aplicação do mapa causal e da matriz de loops para análise de problemas complexos no contexto da esfera pública.

A proposição de ir mais além da análise inicial, de incluir esforços para investigação de problemas em maior profundidade e detalhamento, como a identificação de loops entre duas causas e de circuitos sistêmicos entre dois loops que se relacionam via uma causa comum (loops explosivos"), mostra-se similar aos vantajosos esforços adicionais do "ciclo duplo" de análise proposto por Argyris (1990). Esse "ciclo duplo" de análise das intercausas, ou seja, de loops entre loops causais, torna a abordagem mais precisa e útil para o contexto de problemas complexos. 
O método adotado, design science, mostrou-se bastante pertinente em termos de direcionar as atividades de consolidação de fragmentos de práticas e técnicas aplicadas por pesquisadores em uma abordagem consistente para praticantes não pesquisadores, neste caso, os gestores municipais (Van Aken e Romme, 2009). Os recursos utilizados, as práticas e técnicas, estavam disponíveis em muitos artigos de diferentes décadas e áreas temáticas. Esses recursos eram utilizados como meio, ou seja, aplicados e descritos o suficiente para entender o conhecimento científico a ser validado, que não era o próprio método ou técnica em questão. Assim, as sete atividades descritas detalhadamente e resumidas na seção de procedimentos da pesquisa caracterizam-se como o artefato, objeto central da abordagem design science, que foi desenvolvido, descrito e validado por esta pesquisa. Os gestores, que analisam problemas complexos, constituem o grupo de praticantes definidos como usuários do artefato.

Os artefatos tecnológicos, válidos cientificamente, necessitam, também, atender aos pressupostos da teoria de qualidade, abrangendo simplicidade, precisão e generalização (Langley, 1999), e aplicando-os para análise do artefato (método) apresentado para resolução de problemas complexos, temos:

Precisão - obtida pelo aporte científico associado ao método, como a incorporação de técnicas da análise de redes, bem como a aplicação de conceitos de arquétipos sistêmicos da teoria geral de sistemas (amplificação de desvios, limitação de desvios e inter-relação de loops de amplificação);

Simplicidade - o método mostra-se bastante simples, principalmente quando se trabalha com softwares que realizam os cálculos de indicadores de redes e as operações com matrizes que resultam na matriz de loop;

Generalização — associada à possibilidade de uso junto a qualquer problema, neste caso, os que apresentem um conjunto de causas e, principalmente, interdependência entre estas, configurando um contexto complexo para análise.

Quanto ao conteúdo específico associado ao problema da falta de vagas em creches, mais especificamente, a lista das 32 causas identificadas, estas não podem ser extrapoladas para outras prefeituras, considerando o caráter único de cada uma destas entidades. Apesar desta limitação da pesquisa, a lista das 32 causas pode ser compreendida como um conjunto sugestivo para provocar a geração de ideias iniciais ou verificar a completude de problemas identificados em trabalhos futuros junto às prefeituras. Nas duas situações, a lista serve para identificar possíveis agrupamentos de causas, bem como apresentar exemplos específicos de causas destes tipos, para o problema da falta de vagas em creches.

A presente pesquisa percebeu a possibilidade de a variável "continuidade do governo municipal" impactar na quantidade e diversidade das causas associadas ao problema, conforme relatado nas análises. Assim, recomenda-se como continuidade desta pesquisa endereçar este aspecto, trabalhando com dois grupos distintos de prefeituras: as que apresentam continuidade de governo, mais precisamente com prefeitos reeleitos e sem alteração de partido político, e as que caracterizam mudança significativa de governo, tanto de prefeito, quanto de partido político. 


\section{Referências}

AAKER, David A. Strategic marketing management. 7. ed. Hoboken: Wiley, 2005.

ARGYRIS, Chris. Overcoming organizational defenses: facilitating organizational learning. Boston: Allyn \& Bacon, 1990.

AXELROD, Robert. The structure of decision. Princeton, NJ.: Princeton University Press, 1976.

BOUGON, Michel. G. Congregate cognitive maps: a unified dynamic theory of organization and strategy. Journal of Management Studies, v. 29, n. 3, p. 369-389, 1992.

BOUGON, Michel G.; KOMOCAR, John M. Directing strategic change: a dynamic holistic approach. In: HUFF, Anne S. (Ed.). Mapping strategic thought. Nova York: Wiley, 1990.

BOUGON, Michel G.; WEICK, Karl E.; BINKHORST, Din. Cognition in organizations: an analysis of the Utrecht Jazz Orchestra. Administrative Science Quarterly, v. 22, n. 4, p. 606-639, 1977.

BRASIL. Constituição da República Federativa do Brasil, 1988. Disponível em: <www.planalto.gov. br/ccivil_03/Constituicao/Constituicao.htm>. Acesso em: 10 mar. 2013.

BRASIL. INSTITUTO BRASILEIRO DE GEOGRAFIA E ESTATÍSTICA. Pesquisa Nacional por Amostra de Domicílios, Pesquisa Básica - 2001 a 2011, 2013. Disponível em: <www.sidra.ibge.gov.br/pnad/ pnadpb.asp?o=3\&i=P>. Aceso em: 7 abr. 2013.

BRASIL. Lei 8.069, de 13 de julho de 1990. Dispõe sobre o Estatuto da Criança e do Adolescente e dá outras providências, 1990. Disponível em: <www.planalto.gov.br/ccivil_03/Leis/L8069.htm>. Acesso em: 10 mar. 2013.

CRESWELL, John W. Projeto de pesquisa: métodos qualitativo, quantitativo e misto. 2. ed. Porto Alegre: Bookman, 2007.

DATA Popular. Creche como demanda das mulheres, 2012. Disponível em: <www.agenciapatriciagalvao.org.br/images/stories/PDF/pesquisas/Creches_-_Divulgacao.pdf>. Acesso em: 11 abr. 2013.

EDEN, Colin. Analyzing cognitive maps to help structure issues or problems. European Journal of Operational Research, v. 159, n. 3, p. 673-686, 2004.

EDEN, Colin; ACKERMANN, Fran. Making strategy: the journey of strategic management. Londres: Sage Publications, 1998.

EDEN, Colin; JONES, Sue; SIMS, David. Messing About in Problems. Oxford: Pergamon Press, 1983.

GAB, Oliver et al. Anatomy of knowledge bases used in design science research. In: PEFFERS, Ken; ROTHENBERGER, Marcus; KUECHLER, Bill (Ed.). Design science research in information systems: advances in theory and practice. Berlim: Springer Berlin Heidelberg, 2012. p. 328-344.

GREGOR, Shirley; HEVNER, Alan R. Positioning and presenting design science research for maximum impact. MIS Quarterly, v. 37, n. 2, p. 337-355, 2013. 
G1.GLOBO. Falta de vagas em creches de SP atinge 175 mil crianças, 2012. Disponível em: < http:// g1.globo.com/sao-paulo/noticia/2012/02/falta-de-vagas-em-creches-de-sp-atinge-175-mil-criancas. html>. Acesso em: 7 mar. 2013.

HEVNER, Alan R. et al. Design science in information systems research. MIS Quarterly, v. 28, n. 1, p. 75-105, 2004.

IIVARI, Juhani. A paradigmatic analysis of information systems as a design science. Scandinavian Journal of Information Systems, v. 19, n. 2, p. 39-64, 2007.

KELLY, George A. The psychology of personal constructs. Nova York: Norton, 1955.

KETTINGER, William J.; TENG, James T. C.; GUHA, Subashish. Business process change: A study of methodologies, techniques, and tools. MIS Quarterly, v. 21, n. 1, p. 55-80, 1997.

KUECHLER, Bill; VAISHNAVI, Vijay. Theory development in design science research: anatomy of a research project. European Journal of Information Systems, v. 17, n. 5, p. 489-504, 2008.

LANGLEY, Ann. Strategies for theorizing from process data. Academy of Management Review, v. 24, n. 4, p. 691-710, 1999.

MASUCH, Michael. Vicious circles in organizations. Administrative Science Quarterly, v. 30, n. 1, p. 14-33, 1985.

MONTIBELLER, Gilberto; BELTON, Valerie. Causal maps and the evaluation of decision options - a review. The Journal of the Operational Research Society, v. 57, n. 7, p. 779-791, 2006.

NELSON, Reed E.; MATHEWS, Michael K. Cause maps and social network analysis in organizational diagnosis. The Journal of Applied Behavioral Science, v. 27, n. 3, p. 379-397, 1991.

NICOLINI, Davide. Comparing methods for mapping organizational cognition. Organization Studies, v. 20, n. 5, p. 833-860, 1999.

OSBORN, Alex. Applied imagination. 3. ed. Buffalo, NY: Creative Education Foundation, 1993.

SCAVARDA, Annibal J. et al. A methodology for constructing collective causal maps. Decision Sciences, v. 37, n. 2, p. 263-283, 2006.

SENGE, Peter M. et al. The fifth discipline fieldbook. Nova York: Doubleday, 1994.

VAN AKEN, Joan E.; ROMME, Georges. Reinventing the future: adding design science to the repertoire of organization and management studies. Organization Management Journal, v. 6, n. 1, p. 2-12, 2009.

VON BERTALANFFY, Ludwig. Teoria geral dos sistemas. 4. ed. Petrópolis: Vozes, 2008.

VOYER, John J.; FAULKNER, Robert R. Cognition and leadership in an artistic organization. In: PEARCE II, John A.; ROBINSON, Richard B. (Org.). Academy of Management Best Paper Proceedings, Nova York, 1986. p. 160-164.

WASSERMAN, Stanley; FAUST, Katherine. Social network analysis. Cambridge: Cambridge University Press, 1994. 
WEBER, Paula S.; MANNING, Michael R. Cause maps, sense making, and planned organizational change. The Journal of Applied Behavioral Science, v. 37, n. 2, p. 227-251, 2001.

WEICK, Karl E. Sense making in organizations. Thousand Oaks, CA: Sage, 1995.

José Osvaldo De Sordi é docente-pesquisador permanente do programa de mestrado em Administração das Faculdades Metropolitanas Unidas (FMU) e colaborador do programa de mestrado em administração da Faculdade Campo Limpo Paulista (Faccamp). E-mail: osdesordi@gmail.com.

Reed Elliot Nelson é docente-pesquisador dos programas de mestrado e doutorado em administração da Universidade Nove de Julho (Uninove). E-mail: renelson@siu.edu.

Pedro Reis Galindo é secretário de finanças do município de Jundiaí (SP). E-mail: pedrogalindo@terra. com.br. 